\title{
LEIBNIZ E OS ANIMAIS
}

\author{
Ulysses Pinheiro \\ $\mathrm{UFRJ} / \mathrm{CNPq}^{1}$
}

\begin{abstract}
RESUMO: A continuidade e a ruptura entre homens e animais apontam para um impasse interno da filosofia de Leibniz. Por um lado, ele deve poder dar conta da emergência do que é propriamente humano a partir da animalidade obedecendo ao Princípio de Continuidade (isto é, ao Princípio de Razão Suficiente); por outro lado, a racionalidade introduz uma diferença qualitativa que não parece poder ser redutível a uma mera distinção de graus. Sem procurar eliminar essa tensão conceitual, o artigo trata de entender suas consequências para o projeto filosófico de Leibniz e da Modernidade como um todo.
\end{abstract}

PALAVRAS-CHAVE: Leibniz, homem, animal, diferença antropológica.

\begin{abstract}
The continuity and the rupture between men and animals point to an internal tension within Leibniz's philosophy. On the one side, he must be able to explain, taking as a point of depart animal nature, the emergence of what is characteristically human, following in this way the Principle of Continuity (i.e. the Principle of Sufficient Reason); on the other side, rationality introduces a qualitative difference that does not seem to be reducible to a mere distinction of degrees. The aim of the article is not to try to eliminate this conceptual tension, but to understand its consequences to Leibniz's philosophical project and to Modern philosophy in general.
\end{abstract}

KEYWORDS: Leibniz, man, animal, anthropological difference.

O objetivo deste texto é examinar, através de um exemplo particular, as relações de continuidade e de ruptura que uma longa tradição metafísica estabeleceu entre os domínios do humano e do animal. Segundo sugere Giorgio Agamben, em seu recente livro $O$ aberto, essas relações constituem "uma operação metafísico-política fundamental, na qual apenas alguma coisa como

1 Este artigo foi escrito graças ao apoio de um auxílio concedido pelo CNPq através da Chamada MCTI/CNPQ/Universal 14/2014, em um projeto de pesquisa intitulado 0 conceito de animal na Monadologia de Leibniz. 


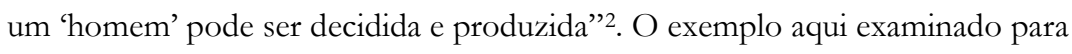
ilustrar essa "decisão fundamental" será um texto capital do século XVIII, a Monadolagia de G. W. Leibniz, onde se trata de estabelecer os princípios metafísicos das "ciências da vida". Ao final, veremos como uma tensão irresolvida entre a continuidade e a ruptura das características humanas e animais estrutura esse texto.

Um dos propósitos da Monadologia é estabelecer o limite ou a fronteira que separa o homem do resto dos animais. Ora, é só ao traçar esse limite - que é, de certa forma, interno ao próprio homem, na medida em que ele é também um animal ${ }^{3}$ - que a limitação da própria racionalidade finita por aquilo que a ultrapassa (Deus) pode ser pensada. Nos dois casos, portanto, o contraste com o "outro" da racionalidade dos homens deve ser inteiramente percorrido e demarcado, estabelecendo assim o lugar da humanidade em uma escala contínua que, partindo de Deus, estende-se até os seres menos perfeitos. Mas a dificuldade, em ambos os casos, está em pensar em uma ruptura inscrita no contínuo.

As teorias da geração dos animais no século XVII defrontavam-se com um dilema: por um lado, tanto as teses da geração espontânea quanto as da epigênese espiritual tinham cada vez menos adeptos; por outro lado, as explicações epigenéticas mecânicas tampouco pareciam inteiramente 


\section{Dossiê Leibniz, Dissertatio - Volume Suplementar 03 I UFPel [2016]}

satisfatórias, pois não davam conta da origem e da complexidade do fenômeno da vida. A tese das "naturezas plásticas imateriais" de Ralph Cudworth ${ }^{4}$, exemplo de postulação de epigênese através de uma forma imaterial adicionada ao material uterino no momento da concepção, indica, nesse sentido, apenas a sobrevivência dessas antigas teorias no novo contexto científico. Confrontado com esse dilema, Leibniz escolhe, como de hábito, um caminho radical: entre optar por uma explicação puramente mecânica da geração dos animais e pela adoção de um princípio imaterial extrínseco, ele recusa ambos; se nenhuma das duas vias é capaz de explicar a geração dos animais, diz Leibniz, é preciso então abandonar uma suposta evidência, a saber: a ideia mesma de que há algo como a "geração" de animais. Esses últimos, tanto quanto as plantas, são imortais, e todo nascimento é, na verdade, uma transformação ${ }^{5}$. De modo apenas aparentemente paradoxal, o preformismo é, assim, adotado como uma maneira extrema de salvar o mecanicismo, que pode agora ser usado para explicar não a geração - que não existe -, mas apenas as diversas transformações por que passam os seres vivos ${ }^{6}$. O problema, no entanto, surge quando se trata de explicar mecanicamente, levando em conta a aplicação do Princípio de Continuidade na matéria extensa, como os animais espermáticos passam "a um maior teatro" e desenvolvem a racionalidade própria dos animais humanos.

\footnotetext{
${ }^{4} \mathrm{Cf}$. The True Intellectual System of the Universe: the first part, wherein all the reason and philosophy of atheism is confuted and its impossibility demonstrated (1678).

5 Considerações sobre os princípios vitais e as naturezas plásticas - GP VI 543.

${ }^{6}$ Sobre esse ponto, cf. Smith (2011), pp. 169-170.
} 
O mesmo problema também surge em um nível que poderíamos chamar de metateórico, a saber: nas condições que deve cumprir uma descrição acurada do aperfeiçoamento constante de todas as criaturas em direção a Deus, pois o Princípio de Continuidade deveria poder explicar (ou pelo menos deveria ser compatível com) a distinção qualitativa introduzida nos animais humanos pela posse e pelo uso da razão. O $\int 74$ da Monadologia, após descartar a tese da geração espontânea, substituindo-a pela tese da preformação, caracteriza o ato de concepção como o meio pelo qual o ser vivo "foi disposto a uma grande transformação para se tornar um animal de outra espécie"”. Leibniz é, neste momento, um dos inauguradores de uma "história das espécies", pelo menos na medida em que afirma que os animais necessariamente realizam um percurso temporal através das espécies. A passagem do tempo torna-se, portanto, parte do que eles são essencialmente, na medida em que o próprio tempo é estruturado teleologicamente. A ideia de que as espécies vivas deveriam ser pensadas segundo categorias históricas terá, como sabemos, uma frutífera linhagem (lembremo-nos, por exemplo, dos “mecanismos orgânicos" de Louis Bourguet ${ }^{8}$ ou do verbete Animal da Enciclopédia, no qual Diderot falará da "sucessão, renovação e duração das espécies""). É verdade que a teoria da preformação, segundo a qual todas as transformações que ocorrem após a concepção já estão

7 GP VI, 619.

${ }^{8}$ Cf. Louis Bourguet, em suas Lettres philosophiques sur la formation des sels et des cristaux et sur la génération et le mécanisme organique des plantes et des animaux. (1729). Citado por Roger(1990).

9 Encyclopédie ou Dictionnaire raisonné des sciences, des arts et des métiers, par une Société de Gens de lettres, Vol. 1, p. 470. 


\section{Dossiê Leibniz, Dissertatio - Volume Suplementar 03 I UFPel [2016]}

figuradas em seus germes, é entendida, no contexto do leibnizianismo, a partir de uma cosmogonia, de tal modo que, ao criar o mundo, Deus criou os seres vivos já dotados virtualmente de todas as suas transformações futuras - quer essas últimas ocorram "naturalmente" ou por um "milagre". Entretanto, isso não deve diminuir a importância da tese continuista, presente, por exemplo, nas diversas vezes em que Charles Darwin cita o filosofema leibniziano segundo o qual "A natureza não dá saltos".

Mas o artigo seguinte da Monadologia, o $₫ 75$, parece restringir o alcance da evolução a apenas alguns animais: dentre todos eles, afirma Leibniz aí, os que "permanecem em sua espécie, isto é, a maior parte, nascem, se multiplicam e são destruídos como os grandes animais", havendo apenas "um pequeno número de Eleitos, que passa a um maior teatro" ${ }^{10}$. Logo a seguir, porém, o $\$ 76 fará uma correção importante a essa tese: assim como a geração deve ser entendida através da tese da preformação, indo ao infinito em direção ao passado, também a morte é um tipo de transformação ao infinito. Logo, conclui Leibniz, se "o animal não começa nunca naturalmente, ele não termina naturalmente tampouco" ${ }^{11}$. Esse trecho da Monadologia propõe, então, uma divisão no interior do reino animal: os "grandes animais" - classe na qual está incluído o homem - são destinados à salvação, enquanto os animais microscópicos ou bem nascem e morrem naturalmente ou bem desfrutam de

$11 \mathrm{GP} \mathrm{VI,} 620$. 
uma vida sem começo e sem fim em sua própria espécie, cada nova geração sendo entendida, portanto, como uma nova metamorfose.

Neste momento do texto, Leibniz não opta claramente por uma dessas duas alternativas, mas a segunda delas parece a mais coerente com a tese, formulada universalmente, que assimila a geração à preformação. Além disso, outros trechos da Monadologia nos forçam a escolher a segunda alternativa, isto é, a que afirma que os animais microscópicos desfrutam de uma vida sem começo e sem fim em sua própria espécie: as "máquinas da natureza” são, todas elas, divisíveis ao infinito, o que significa que, não podendo chegar a partes nãomaquínicas, o animal nunca pode ser inteiramente desmembrado - sua divisibilidade infinita expressa, na matéria, a simplicidade monádica -, e é justamente porque é divisível ao infinito sem que nunca um novo animal deixe de surgir que ele não pode sofrer o tipo de divisibilidade que implica destruição $\mathrm{O}^{12}$.

Entretanto, porque a ideia mesma de existência é pensada a partir de um aperfeiçoamento constante de todas as criaturas, Leibniz também deveria, aparentemente, comprometer-se com a tese contrária, a qual, de fato, ele parece ter por vezes adotado - inspirada, sem dúvida, pela Cabala cristianizada com a qual tinha contato -, a saber: a tese da "salvação universal"13: todos os seres vivos serão salvos, todos terão a oportunidade de "passar a um maior teatro". Se for 


\section{Dossiê Leibniz, Dissertatio - Volume Suplementar 03 I UFPel [2016]}

assim, todas as criaturas, mesmo as mônadas que vivem em um estado de completo aturdimento, desprovidas de percepções sensíveis distintas, estariam destinadas a, um dia, virem a ser animais racionais, e a progredirem indefinidamente em direção a uma cada vez maior racionalidade. Uma heresia, sem dúvida, mas também um princípio particularmente útil em seu combate contra o quietismo Jansenista. Portanto, da imortalidade de todos os animais inclusive os animais microscópicos e espermáticos -, seguir-se-ia que todos eles progrediriam continuamente até o estado humano, e daí para formas de vida superiores. Voltaremos ao caso da possível salvação dos animais microscópicos mais adiante.

Desde já, porém, notemos que há uma outra tese importante da Monadologia que, ao mesmo tempo, postula que haja algum tipo de continuidade entre os animais microscópicos (ou pelo menos uma classe deles, alguns dos animais espermáticos - ou, ainda, uma sua subclasse, a dos animais espermáticos que foram "eleitos") e os "grandes animais" e sugere haver também uma ruptura. Trata-se da tese enunciada no $₫ 82$, segundo a qual

há isso de particular nos Animais racionais, que seus pequenos Animais Espermáticos, na medida em que são apenas isso, têm somente Almas ordinárias ou sensitivas; mas, desde que aqueles que são eleitos, por assim dizer, chegam, por uma concepção real, à natureza humana, suas almas sensitivas são elevadas ao grau da razão e à prerrogativa dos Espíritos ${ }^{14}$.

14 GP VI, 621. 
A tensão entre dois modelos explicativos aparece aqui claramente. Por um lado, há uma passagem gradual de espécies animais à espécie humana; por outro lado, há um momento crucial - cujo aspecto algo milagroso assemelha-se em parte à sagrada concepção de Maria - no qual uma alma racional é repentinamente "elevada", numa espécie de "arrebatamento", a um estado qualitativamente distinto do dos outros animais. Esse mesmo $\int 82$ remete os leitores para os $₫ 91$ e $\ 397$ da Teodiceia, mas tal remissão, ao invés de resolver a referida tensão, a aprofunda. De fato, no $\ 91$, Leibniz afirma que tem dificuldade para entender que haja "um meio natural de elevar uma alma sensitiva ao grau da alma racional", o que o leva a admitir que "Deus tenha dado a razão a essa alma por uma operação particular, ou, se quiserdes, por uma espécie de transcriação" ${ }^{15}$. Por outro lado, no $\ 397$, ele afirma que preferiria se “passar do milagre na geração do homem", propondo então - e aqui ele antecipa a tese sobre os animais microscópicos exposta no $\int 75$ da Monadologia já mencionada acima - que a divisão não se encontra propriamente entre o homem e os animais, mas sim entre os animais dotados de corpos orgânicos "preformados e predispospos a tomar um dia a forma humana" e "os outros pequenos animais ou viventes seminais, onde nada de semelhante é preestabelecido como sendo essencialmente diferente deles"16. Não haveria, portanto, salvação universal, pois os animais microscópicos permaneceriam

16 GP VI, 352. 


\section{Dossiê Leibniz, Dissertatio - Volume Suplementar 03 I UFPel [2016]}

sempre em sua própria espécie, alijados da história. No entanto, a teoria de Leibniz encontra-se aqui claramente em um impasse: como o perfeccionismo histórico parece ter sido deduzido da imortalidade dos animais, o abandono do primeiro deveria implicar o abandono do segundo; ora, a negação desse último deixaria Leibniz sem uma explicação para a geração dos "grandes animais", especialmente porque teria de descartar sua origem a partir dos animais espermáticos, reconduzindo-o perigosamente às teses da geração espontânea e da epigênese - as quais, porém, não satisfazem o Princípio de Razão Suficiente.

Onde quer que o corte seja feito - quer ele se localize entre os animais macroscópicos e os microscópicos, quer entre os homens e os demais animais -, a dificuldade permanece. Detenhamo-nos por ora no caso das marcas características do humano. Por um lado, Leibniz parece conceber a passagem da natureza sensitiva para a natureza racional como uma mudança gradativa e contínua em uma escala de aperfeiçoamento, o que é inteiramente concordante com sua concepção da realidade como uma série ordenada de graus de perfeição; por outro lado, ele parece supor que, quando o animal chega à forma humana, ocorre uma mudança qualitativa, não mais explicável em termos de séries homogêneas. A dificuldade pode ser melhor compreendida se traduzirmos esse problema ontológico para o vocabulário epistêmico ${ }^{17}$. De fato, Leibniz deve poder explicar o que ocorre ao animal do ponto de vista do corpo (isto é, suas

17 A distinção entre uma perspectiva ontológica e uma epistêmica não pode, ao menos no caso em questão, ser mais do que uma distinção de razão, pois a "diferença específica" que separa os homens dos animais é justamente a possa e uso da razão, isto é, da faculdade de conceber verdades necessárias. 
metamorfoses) também do ponto de vista da alma (isto é, de suas capacidades cognitivas). Dessa última perspectiva, deveria haver, aparentemente, uma espécie de acúmulo gradativo de conhecimentos sensíveis, que chegariam a um certo ponto de maturação ou de completude, a partir do qual deveríamos dizer que algumas almas passam a merecer o nome de "Espíritos", capazes de se referir a si mesmos através do uso do pronome "eu". Ou ainda: eles passariam a ser imagens não apenas da Natureza, cuja realidade é contingente, mas do próprio Autor da Natureza, dotado de uma essência necessária, “cada Espírito sendo como uma pequena divindade em seu departamento" (Monadologia, $\mathbb{S}$ $83)^{18}$. Contra essa figuração de um progresso gradativo entre os animais apenas sensitivos e os animais humanos, porém, devemos nos recordar do modo como a ideia mesma de verdade necessária, objeto privilegiado do conhecimento racional, fora introduzida na Monadologia. No $₫ 30$, o conhecimento das verdades necessárias e de suas abstrações é o meio a partir do qual "somos elevados aos Atos reflexivos, que nos fazem pensar no que se chama Eu'19. Deve-se notar o uso da voz passiva: "somos elevados" [nous sommes élevés] à reflexão pelo conhecimento das verdades necessárias. Poder pensar no "eu" como a unidade de um múltiplo de percepções só é possível porque podemos pensá-lo através das noções de Ser e de Substância, de Simples e de Complexo. Isso significa que as próprias verdades necessárias - ao menos as mais primitivas dentre elas - 


\section{Dossiê Leibniz, Dissertatio - Volume Suplementar 03 I UFPel [2016]}

devem ser dadas, sem nenhum processo de descoberta ou de constituição, como condição de possibilidade da própria apercepção. Portanto, qualquer gênese gradativa da "Alma racional", que parta do conhecimento sensível e chegue ao uso da razão, parece dever ser descartada - ainda mais quando se leva em conta que uma verdade necessária e universal depende de uma faculdade cognitiva que não pode proceder por indução e abstração, pois essas últimas só produzem verdades contingentes e (mais ou menos) gerais.

Mas essa dificuldade talvez seja apenas aparente, pois o modo como cada homem adquire conhecimentos racionais, saindo aos poucos de um estado infantil de obscuridade e confusão para a maioridade racional, poderia ser usado para compreender analogicamente o surgimento da racionalidade ao longo da história animal. Dez anos antes de escrever a Monadologia, Leibniz já havia explicado, nos Novos ensaios sobre o entendimento bumano, como as ideias inatas devem ser entendidas: elas são disposições inatas, o que, de um ponto de vista ontológico, representa um meio-termo entre uma percepção atualmente consciente e a mera faculdade passiva para adquiri-las. Nesse sentido, "a alma pode ter essa coisa [i.e., a coisa conbecida] nela sem que se tenha dela apercebido"20. Da mesma maneira, ao longo de sucessivas metamorfoses, as almas puramente sensitivas dos animais adquiririam almas racionais humanas: por um crescente esforço de atenção, a alma, movendo-se inicialmente em meio às ideias obscuras e confusas das sensações, aos poucos como que dissiparia a escuridão e

${ }^{20} \mathrm{NE}$, Livro I, Cap. 1, § 5, p. 60. 
"isolaria" noções inatas claramente percebidas - um processo necessariamente lento e penoso, já que é "impossível visar todas de início e de uma só vez"21. A história das espécies seria assim um espelho da história de cada um de seus membros: a gênese gradativa da razão seria assimilada a uma separação ou atenção seletiva, obtida através da ordenação e da doutrina, como é dito no Livro I dos Novos ensaios ${ }^{22}$, fazendo com que a disposição ativa da mente se voltasse para percepções que sempre já estiveram lá virtualmente. Em suma, o processo gradativo de eliminação da obscuridade daria lugar a um ato inaugural de intuição intelectual, que ocorreria, por definição, em um instante, permitindo, assim, o surgimento da potência inata do intelecto. Ou ainda: seria preciso supor que há sempre mais nas mônadas do que uma mera faculdade em potência, adormecida, de perceber as ideias inatas; além disso, seria preciso supor que há também nelas uma atividade racional em exercício constante, mesmo que, nas mônadas mais primitivas, tal disposição praticamente não possa se distinguir da atividade interna de produção das percepções obscuras e confusas. Leibniz poderia assim manter, contra Locke, que há uma distinção qualitativa forte entre homens e animais, dependente da posse inata de uma faculdade para perceber verdades necessárias, embora pudesse concordar com ele que, em outro sentido, tal distinção seria apenas de graus. 


\section{Dossiê Leibniz, Dissertatio - Volume Suplementar 03 I UFPel [2016]}

Tal solução, entretanto, deixa subsistir um ponto cego no momento crucial da explicação genética da racionalidade. De fato, se o processo de progressiva atenção seletiva pode explicar, sem dificuldade, a emergência gradativa das "percepções distinguidas" (as sensações claras) a partir da multiplicidade obscura e confusa característica das "mônadas nuas", o mesmo não se dá - ao menos não no mesmo sentido - com a aquisição das verdades necessárias. O momento no qual, através de seus órgãos sensíveis, um animal passa a reconhecer sensações distintas - comida, água, abrigo, perigo - pode, sem maiores problemas, ser figurado como uma passagem de graus (pensemos na seguinte situação: entramos em um quarto obscuramente iluminado e, aos poucos, à medida que nossos olhos se ajustam à luz ambiente, passamos a enxergar os objetos nele dispostos). Ou seja, a cada momento as sensações vão ganhando mais e mais nitidez, sem que haja um ponto crucial no qual elas se tornam apercepções conscientes. A expressão "percepções inconscientes" significa, portanto, percepções minimamente conscientes, e a consciência dos animais pode ser explicada através de uma apercepção de si obscura e confusa ${ }^{23}$. O mesmo tipo de processo de atenção gradativa, porém, não pode explicar a tomada de consciência das ideias inatas do intelecto puro: essas últimas devem se tornar conscientes instantaneamente, sem passagem de graus. O necessário deve aparecer como necessário imediatamente, por um ato discreto de intuição intelectual. Ora, o abismo qualitativo introduzido entre essas duas formas de

${ }^{23}$ Cf. Kulstad (1991). 
percepção contraria o Princípio de Razão Suficiente, segundo o qual cada percepção tem sua origem em uma percepção anterior, ainda que menos distintamente percebida, e, portanto, contraria a possibilidade mesma de uma explicação racional completa da racionalidade das mônadas.

Ou seja, ao abrir mão de um milagre contínuo para explicar o surgimento da racionalidade nos adultos humanos (no nível individual) ou nos animais humanos (no nível da espécie), Leibniz o faz ao preço de abandonar, simultaneamente, uma explicação continuísta da consciência, entendida como atenção ordenada por graus. Ele não parece, portanto, ter meios para explicar como, por um processo de esclarecimento progressivo, o conhecimento empírico "transforma-se" em um conhecimento racional. É verdade que, porque as sensações envolvem uma infinidade de pequenas percepções insensíveis, certamente nenhuma análise realizada por uma mente finita poderia “intelectualizar os fenômenos", para usar a expressão de Kant. No entanto, deveria ser possível descrever, em termos ideais, tal gênese, mesmo que sua descrição detalhada fosse exclusiva de uma mente infinita. Mas, se a crítica anterior for válida, não parece ser possível, por princípio, explicar a formação da racionalidade: o procedimento de atenção seletiva pareceria só poder ser entendido nos moldes de uma análise gradativa - e é significativo, nesse sentido, que Leibniz, nos Novos ensaios, tenha simplesmente ignorado as várias dificuldades formuladas por Locke, no trecho correspondente do Ensaio, 


\section{Dossiê Leibniz, Dissertatio - Volume Suplementar 03 U UFPel [2016]}

relativas à caracterização das ideias inatas a partir da expressão temporal "quando se chega ao uso da razão"24.

Seria possível, é certo, abandonar qualquer limite claro entre homens e animais, de tal modo que os "grandes animais" - e seus respectivos "animais espermáticos" - seriam desde sempre já sujeitos racionais, ainda que dotados de um grau mínimo de racionalidade, assim como os homens seriam eles também sujeitos empíricos imperfeitamente desenvolvidos (e, diante do aperfeiçoamento infinito aberto aos homens, qualquer distância entre eles e os outros animais seria desprezível diante da distância infinita que separaria ambos do intelecto do Ente perfeitíssimo). Que Leibniz evite tirar essa consequência o atesta toda a parte final da Monadologia, bem como muitos outros textos da mesma época, nos quais a "Sociedade dos Espíritos com Deus" (Monadologia, $\$$ $84)^{25}$ introduz uma relação qualitativamente diferente da que une a divindade aos animais ordinários, destituídos de espírito - nesse último caso, a relação de Deus com eles é apenas a de um inventor com "sua Máquina".

O que devemos concluir a partir da constatação dessa dificuldade presente nos textos de Leibniz acerca da animalidade do homem e das relações do homem com os outros animais? Seria muito empobrecedor simplesmente

\footnotetext{
24 Note-se, de passagem que um problema semelhante a esse manifesta-se na tentativa leibniziana de compatibilização entre liberdade e determinismo através do uso da noção de análise infinita; de fato, a ideia de que a contingência requerida pelas decisões livres pode ser explicada pelo fato de que os fatos contingentes envolvem uma análise que vai ao infinito não parece explicar por que a infinitude do intelecto de Deus não poderia perceber tais séries infinitas a partir de um ponto de vista que lhes restituísse a necessidade absoluta.

$25 \mathrm{GP} \mathrm{VI,} 621$.
} 
decretar sua inconsistência irremediável, abandonando-os ao esquecimento dos projetos fracassados - ainda mais quando nos lembramos de que, com todas as suas tensões internas e problemas explicativos, esses textos fazem parte da constituição daquilo que nos tornamos nos últimos séculos, ou seja, daquela “decisão metafísica" da qual falava Agamben, também caracterizada por ele através do conceito de "máquina antropológia", ou seja, de um mecanismo simbólico de produção histórica da nossa compreensão do que significa "ser homem". "Não rir, não zombar, não detestar, mas antes compreender", já nos aconselhava Spinoza; diante de um aparente paradoxo dessa monta, tanto a atitude de simples recusa quanto a de tentar eliminar as tensões por uma interpretação conciliadora parecem ser tentações a serem vistas com certa suspeita. Situar-se na própria tensão e tentar captar o quanto dela é condição de possibilidade do discurso mais amplo no qual está contida talvez seja o passo mais prudente e mais produtivo. Ao invés de avançar, pois, deixemo-nos quedar neste ponto.

Leibniz encontra-se na encruzilhada que separa uma concepção clássica de sujeito - exemplificada, por exemplo, por Descartes - de nosso conceito moderno, pós-kantiano, de subjetividade. A apercepção, para Leibniz, representa uma pura atividade de síntese de um múltiplo de percepções na unidade monádica, de tal modo que, do ponto de vista da mônada, "ser" e "ser percebido" são indistinguíveis. Dito de outra forma, não é possível para nenhuma mônada - nem para as "mônadas nuas" - existir sem um grau mínimo 


\section{Dossiê Leibniz, Dissertatio - Volume Suplementar 03 I UFPel [2016]}

de apercepção. Quando essa apercepção é dada através da razão, porém, a ideia de "eu" significa a autopercepção clara e distinta de si mesmo como um agente operador da síntese do múltiplo. Como o múltiplo é, por definição, alteridade a si, ou seja, alteridade à unidade monádica, o "eu" concebe-se a si mesmo como a perspectiva pela qual fenômenos corporais são visados.

Ora, o "eu" percebe-se a si mesmo como um ente contingente, ou seja, que poderia não existir. A apercepção racional, no entanto, como nos ensina o \30 da Monadologia, tem por condição de possibilidade a contemplação prévia de verdades necessárias e universais - isto é, de ideias inatas. O "eu”, ao se figurar como um ser contingente, deve fazê-lo, ao mesmo tempo, pela apreensão de si mesmo expressa em termos de verdades necessárias. À primeira vista, tal duplicidade de registros não parece oferecer nenhum problema: afinal, uma proposição tal como, por exemplo, “O mundo existe contingentemente" é uma verdade necessária da metafísica, justamente porque é possível formular proposições necessárias sobre o contingente. O fato de o "eu" só poder ser concebido através de conceitos da razão pura, isto é, de verdades eternas e necessárias, não significa que ele mesmo seja dotado de uma existência necessária e eterna; tudo o que parece ser requerido é que ele seja uma representação inteligível de si mesmo, de sua essência, ainda que sua existência seja uma verdade contingente.

Mas o problema metateórico enunciado acima evidencia-se quando a explicação filosófica da natureza humana elaborada por Leibniz tenta dar conta 
do surgimento da faculdade racional que constitui o "eu", pois sua teoria deve garantir a racionalidade da própria explicação. Nesse momento, o Princípio de Razão Suficiente requer que o Espírito figure sua própria essência, reflexivamente, como um elemento do encadeamento de uma série causal natural, isto é, de um fluxo contínuo de essências instanciadas como existências contingentes, figuração essa que, porém, só pode ocorrer se, situando-se "fora" da série, ele se conceber a si mesmo como um elemento externo a ela. Nesse instante, o homem torna-se não mais apenas um "espelho da natureza", mas também um "espelho da divindade", súdito da cidade de Deus. Em outras palavras, a condição mesma para que a continuidade seja reconhecida é que ela já seja representada por um "eu" que, sendo essencialmente racional, não pode pertencer a ela.

O “eu” leibniziano é, sem dúvida, um curioso espelho, que lembra o “espelho tátil" do cego de Puiseaux descrito por Diderot na sua Carta sobre os cegos para uso dos que veem, uma espécie de "espelho finalista" que reflete a imagem de Deus apenas na medida em que a projeta, para além de si, em um reino de causas finais. Como quer que tal espelho funcione, porém, o que importa é notar a dupla exigência decorrente da aplicação irrestrita do Princípio de Razão Suficiente: por um lado, o "eu" deve ser explicado como emergindo de um fundo infinito de percepções obscuras e confusas, o fundo da animalidade que há em nós e dos animais que já fomos; por outro lado, esse mesmo "eu" é qualitativamente distinto da apercepção confusa que os animais têm de si 


\section{Dossiê Leibniz, Dissertatio - Volume Suplementar 03 U UFPel [2016]}

mesmos - e, quando um animal passa à condição humana, ele é elevado em um instante - o instante da concepção, explicita Leibniz - à racionalidade pura. Com essa dupla exigência, Leibniz, ao tentar evitar cair no "abismo" spinozista do necessitarismo - e, de fato, Spinoza nos apresenta uma versão completamente naturalizada do "eu" -, Leibniz, dizíamos, ao tentar evitar cair no "abismo" spinozista, deve de alguma forma puxar-se pelos próprios cabelos.

A mesma dificuldade pode ser formulada em termos mecanicistas da seguinte maneira: se a tese da epigênese for descartada, então não seria possível localizar um instante preciso da concepção dos animais, na medida mesmo em que toda geração é uma transformação. Haveria alguma forma de evitar esse paradoxo? Como vimos acima, a Monadologia reenvia o leitor ao $\$ 91$ da Teodiceia, para que ele procure aí uma explicação do surgimento das almas racionais a partir da vida puramente animal. O conceito central desse trecho da Teodiceia é o de transcriação, o qual, presumivelmente, é distinto da noção ordinária de criação; talvez a compreensão dessa diferença entre os dois conceitos possa eliminar o caráter paradoxal desse momento central da doutrina de Leibniz.

O $\ 91$ da Teodiceia é o ponto de chegada de uma longa discussão sobre a origem das almas (ou formas, segundo o vocabulário aristotélico adotado eventualmente por Leibniz) no contexto do pecado original, cuja questão central é a seguinte: se novas almas são criadas a cada instante, como conceber que elas têm alguma culpa pelo crime de Adão? Duas opiniões teológicas são examinadas nesse momento: em primeiro lugar, a de Santo Agostinho, que é também a de 
muitos luteranos, de acordo com a qual a alma dos organismos é "traduzida" ou seja, transmitida - a partir da alma de seus genitores; em segundo lugar, a tese da criação de novas almas no momento da concepção, "ensinada na maioria das escolas cristãs" (Teodiceia, $\ 86)^{26}$, isto é, pelos católicos. A primeira doutrina preserva o pecado original, que é a herança da alma de Adão a todas as que dele derivaram; a segunda doutrina preserva a inteligibilidade da noção de substância simples, que não pode ser gerada nem destruída naturalmente (Teodiceia, \ 90) ${ }^{27}$. Novamente aqui, ao invés de optar por uma das teorias contrárias, Leibniz pretende preservar ambas. A noção de transcriação viria resolver esse problema, na medida em que, por um lado, seria um acréscimo de perfeição a uma alma animal preexistente ${ }^{28}$ e, por outro lado, envolveria a criação de uma nova realidade - mas não de uma nova substância - por meio de uma operação particular e sobrenatural de Deus. Nesse momento, uma última alternativa - a de que esse acréscimo de perfeição seria o produto de um "meio natural" - é afastada rapidamente por Leibniz com uma breve frase entre parênteses ("o que tenho dificuldade de conceber", Teodiceia, $\ 91)^{29}$.

\footnotetext{
26 GP VI, 149.

27 Essa segunda doutrina teria a desvantagem adicional de implicar que a alma, sendo uma realidade superior ao corpo, seria corrompida no momento mesmo da sua criação, ao "entrar" no corpo que lhe foi assinalado. Cf. Teodiceia, § 397.

${ }_{28}$ Poderíamos duvidar que a primeira propriedade - a culpabilidade universal pelo pecado original - seria preservada por essa noção, já que os animais puramente sensíveis dificilmente poderiam ter herdado a culpa pelo crime de Adão. Uma solução possível para esse problema seria propor que o pecado original é atribuído à alma de todos os animais que, desde toda a eternidade, já estão predestinados a tornar-se homens. Deixemos de lado, entretanto, essa questão teológica, e concentremo-nos na questão metafísica.
}

${ }^{29}$ GP VI, 152-153. 


\section{Dossiê Leibniz, Dissertatio - Volume Suplementar 03 I UFPel [2016]}

No outro parágrafo da Teodiceia referido pelo artigo 82 da Monadologia, o \397, Leibniz, como vimos, parece hesitar diante desse milagre constante da transcriação, presumivelmente por ele implicar um tipo de ocasionalismo. Ele volta, então, a considerar a hipótese da tradução, mas de um tipo "mais tratável do que se ensina vulgarmente" 30 , a saber: a tese segundo a qual as almas destinadas a um dia virem a ser racionais já estão contidas em seus antecessores desde o começo dos tempos, de tal modo que, ao contrário da doutrina ordinária, que deixa sem explicação como uma alma deriva de outra, essa versão revisada da doutrina da tradução das almas supõe a tese da preexistência, segundo a qual cada novo organismo está contido no organismo de seus genitores - de tal modo que o corpo de Adão já continha em si a infinidade dos outros corpos vivos que constituíram sua prole, até nossos dias. Que Adão contenha em si seus inumeráveis descendentes, até hoje, explica-se, na teoria leibniziana, pela demonstração de que cada organismo contém em si infinitos outros organismos, existindo então sob a forma de "spermata", ou seja, infinitas mônadas ${ }^{31}$ - Adão poderia, pois, dizer, com propriedade: "Meu nome é multidão". Na correspondência com Des Bosses de 1709, quando já tinha escrito a Teodiceia mas não a tinha ainda publicado, Leibniz defende a possibilidade da transcriação, embora diga, na última carta que trata desse

\footnotetext{
$30 \mathrm{GP} \mathrm{VI,} 353$.

31 Teodiceia, § 91; cf. também carta a Des Bosses de 8 de setembro de 1709 (GP II, 389-391). De que modo, porém, essa relação de continência pode explicar a atribuição do pecado a esses infinitos organismos que "são" Adão é algo que não fica inteiramente claro (ver nota anterior).
} 
assunto, estar mais "inclinado" ("ut potius faveam"32) a sua versão revisada da tradução.

É curioso notar, porém, que, na Teodiceia, seja a transcriação a versão preferida por Leibniz - o que, aliás, ele mesmo admite na carta que dera origem a essa disputa com Des Bosses, datada de 30 de abril de $1709^{33}$. Nessa dança de datas para determinar qual é a posição final de Leibniz sobre esse assunto, a carta final a Des Bosses, que endossa a tese da tradução, pareceria ganhar a disputa, uma vez que ela é posterior à Teodiceia, se não fosse pelo fato de que, na Monadologia, escrita cinco anos depois da referida carta, e dois anos antes da morte de Leibniz, a transcriação da Teodiceia tenha sido reconduzida à condição de tese preferida ${ }^{34}$. De fato, a defesa da reforma do conceito tradicional de tradução é sumariamente refutada pela primeira frase do parágrafo que imediatamente a segue: "Eu sou, no entanto", escreve aí Leibniz, "da opinião do R. P. Malebranche, segundo a qual, em geral, a criação, entendida como se deve, não é tão difícil de se admitir quanto se poderia pensar, e que ela está envolvida de alguma forma na noção da dependência das criaturas" ${ }^{35}$. Segue-se então uma longa citação das Meditações cristãs de Malebranche, na qual a teoria da

32 Carta a Des Bosses de 8 de setembro de 1709 (GP II, 389-391).

${ }_{33}$ Carta a Des Bosses de 30 de abril de 1709 (GP II, 371): "Também defendo isso na dissertação contra Bayle [i.e., a Teodiceia], na medida em que ela [i.e, a transcriação] me parece mais provável do que qualquer outro tipo de criação e mais verdadeira do que a tradução".

${ }_{34}$ Poder-se-ia objetar contra essa conclusão a partir da consideração de que a referência do $\S 82$ da Monadologia ao $\S 397$ da Teodiceia não visa estabelecer a posição definitiva de Leibniz sobre o tema, mas apenas remeter o leitor a uma discussão ainda inconclusiva. Se isso for verdade, é a tese da tradução que passa a ganhar o estatuto de posição final defendida por Leibniz a respeito da aquisição da racionalidade. Como não pretendo, no presente texto, decidir qual dessas duas opções é a verdadeira, posso deixar esse ponto em suspenso.

$35 \mathrm{GP} \mathrm{VI}, 353$. 


\section{Dossiê Leibniz, Dissertatio - Volume Suplementar 03 I UFPel [2016]}

criação contínua de todas as coisas por Deus é exposta. Não é de se estranhar que Leibniz use, a partir deste momento, a expressão “criação" para exprimir o que, antes, ele opusera a esse mesmo termo sob o nome de "transcriação", pois se trata agora, de fato, não da criação simpliciter, mas da criação contínua. Ora, a nona Meditação cristã, pouco antes do trecho citado por Leibniz, havia associado essa doutrina à tese ocasionalista, segundo a qual "Deus não deu uma potência verdadeira às criaturas" ${ }^{\prime 3}$. Deve-se notar que a tese da criação contínua sempre foi usada por Malebranche como um dos principais argumentos a favor do ocasionalismo. Daí por que, na sequência do texto, Leibniz apressa-se a criticar a posição de Bayle, segundo a qual a tese da criação contínua implicaria o caráter inteiramente passivo de nossa alma. Nesse que é o momento final do texto sendo seguido apenas pela transcrição do diálogo de Valla e pela parábola dos mundos possíveis vislumbrados por Teodoro -, Leibniz como que "restringe" o alcance da tese da criação contínua: ela valeria apenas para a passagem entre as espécies, mas não para as ações das almas (substâncias) individuais. Mas essa negação apressada de Leibniz deixa em suspenso como podemos entender positivamente a doutrina da transcriação sem confundi-la com o ocasionalismo de Malebranche. Voltemos um pouco no tempo para tentar elucidar essa questão.

36 Malebranche, Meditations chrétiennes et métaphysiques, 9, ii (Paris : J. Vrin, 1967, p. 96). A dependência contínua de todas as criaturas em relação a Deus é também um dos traços característicos da teologia luterana. Cf., abaixo, na nota 28 , um esboço de discussão sobre a relação das teses sobre a transformação e as tradições teológicas cristã e árabe estudadas por Leibniz ao longo de sua vida. 
Trinta anos antes de escrever a Teodiceia, Leibniz fazia, em 1676, sua longa viagem de Paris a Hannover, onde assumiria o posto de bibliotecário real, conselheiro e historiador da família de Brunswick, quando seu navio ficou retido alguns dias no porto de Londres. Ali, isolado em sua cabine, ele escreveu o que talvez seja o seu diálogo mais "platônico", intitulado De Pacídio a Filaleto ${ }^{37}$, claramente uma projeção da estrutura do Teeteto em seu próprio texto. Foi nesse diálogo, bem como em um pequeno texto posterior do mesmo ano, intitulado Números infinitos ${ }^{38}$, que o termo "transcriação" fora introduzido pela primeira vez em sua obra. Nesse texto de juventude, porém, a tese da transcriação não visava explicar a aquisição de uma nova perfeição pelas almas, mas sim a possibilidade do movimento local dos $\operatorname{corpos}^{39}$. As conclusões que ele tira em relação aos corpos será, entretanto, esclarecedora do modo como ele entenderá, trinta anos depois, os "saltos" produzidos miraculosamente por Deus na produção das almas racionais a partir das almas sensitivas; de fato, a conclusão de Leibniz no diálogo é a de que "o movimento não é contínuo, mas acontece em saltos", isto é, "a matéria é extinguida aqui, e reproduzida ali" ilusão cinemática imaginativa. Como se sabe, Leibniz abandonará mais tarde

37 texto encontra-se na edição de Louis Couturat (OFI, pp. 594-627). No mesmo ano, Leibniz traduziu do grego para o latim dois diálogos de Platão, o Teeteto e o Fedon, com o objetivo de retomar o verdadeiro Platão, especialmente contra as deformações que lhe impôs, a seu ver, o neo-platonismo Renascentista. 38 Escrito em 10 de abril de 1676 (AA VI, 3, p. 500). Larry M. Jorgensen (2013), em sua análise histórica e conceitual desse tema no diálogo De Pacídio a Filaleto, afirma que "Transcreation is a term, apparently coined by Leibniz, to refer to the re-creation of matter by God, 'now here, now there,' which he introduced in On Motion and Matter (AA VI, 3, p. 500). The motion of an infinite line is by leaps because, he says, 'motion is nothing but transcreation'." Jorgensen observa, em uma nota, que. "Leibniz later also speaks of the "transproduction" of things; see AA VI, 3, p. 503".

39 O movimento corporal, segundo o jovem Leibniz, não poderia ser entendido como sendo contínuo.

40 AA VI, 3, pp. 493-494. 


\section{Dossiê Leibniz, Dissertatio - Volume Suplementar 03 I UFPel [2016]}

essa posição, a partir do momento em que reconhece haver uma força intrínseca nas substâncias que explica o movimento; em 1676, porém, o ocasionalismo foi a solução encontrada para explicar a mudança local: como os corpos que mudam de posição pressupõem uma realidade espiritual imutável, deve-se concluir que Deus é a causa imediata de todas as coisas ${ }^{41}$.

Leibniz distingue, no diálogo, dois tipos distintos de "salto", um dos quais é aceitável - é ele que está envolvido na transcriação - e outro, inadmissível. A ideia inaceitável de salto é aquela que envolve a passagem de um ponto para o outro sem que o corpo em movimento passe pelo espaço intermediário entre eles, o que contrariaria a harmonia e beleza do mundo criado por Deus segundo o Princípio de Razão Suficiente - se admitíssemos que há “saltos" que envolvam o ultrapassamento de uma distância, então não haveria nenhuma razão, por exemplo, por que um corpo "saltaria" uma distância $n$ ou uma distância $n+142$. A possibilidade alternativa, a de que o corpo passaria por todos os espaços intermediários, por sua vez, envolve, obviamente, um regresso ao infinito, devido à divisibilidade infinita da matéria e à inexistência de átomos. Eliminadas essas duas alternativas, parece, então, que o movimento é logicamente impossível.

Será justamente o recurso ao ocasionalismo que dará a Leibniz, pelo menos nessa época, a saída para tal impasse, na medida em que ele introduzirá 
um salto perfeitamente admissível, aquele que, envolvendo a recriação dos corpos a cada nova posição de seu percurso, faz dessa existência intermitente uma descontinuidade que não contraria o Princípio de Razão Suficiente, na medida em que transforma a continuidade do movimento em mero fenômeno imaginativo, existindo apenas na mente - isto é, o salto não ocorre através do percurso de qualquer distância, embora pareça percorrê-las todas em um movimento contínuo. É a isso que Pacídio batiza com “o novo, mas muito belo nome de transcriação" 43 . Se alguém pretendesse recusar a ideia de transcriação baseado no Princípio de Razão Suficiente, sugere Leibniz, seria o mesmo que pretendesse afirmar que as ideias de criação e de aniquilação são incompatíveis com esse Princípio, o que, obviamente, não é o caso.

Quando Leibniz vier a abandonar, alguns anos mais tarde, essa explicação ocasionalista do movimento, ele o fará não só porque, como dissemos acima, sua nova posição teórica o levará a afirmar que há um princípio ativo no interior das próprias substâncias, mas também porque, dessa interiorização da força ativa, segue-se que todas as ações das substâncias devem obedecer ao Princípio de Continuidade, derivado ele mesmo do Princípio de Razão Suficiente. Ou seja, ainda que as noções de criação e de aniquilamento não sejam contrárias a esse último, a explicação do movimento local através

\footnotetext{
${ }^{43}$ AA VI, 3, p. 567. Em De Pacidio a Filaleto, Leibniz faz, aparentemente por descuido, duas introduções do termo no texto (a primeira delas por Carinus), como se tivesse esquecido, na segunda vez, que já o havia introduzido pouco antes. No entanto, devemos notar que, na segunda introdução do termo "transcriação", é um outro personagem - Teófilo - que define a palavra "transcriação" a partir de sua origem teológica. Marwan Rashed (2005), pp.: 287-307) sugere que se trata de al-Nazzam.
} 


\section{Dossiê Leibniz, Dissertatio - Volume Suplementar 03 I UFPel [2016]}

delas introduziria uma descontinuidade na natureza incompatível com a continuidade de seu fundamento ontológico, o conatus das substâncias individuais. Nessa fase posterior de suas meditações sobre a natureza do movimento, o mesmo raciocínio que leva Leibniz a rejeitar a solução ocasionalista é aplicado às mudanças qualitativas. Assim, em uma carta a De Volder datada de 3 de abril de 1699 (24 de março, segundo o calendário antigo), Leibniz afirma: "O mesmo, pois, proponho que ocorre não somente na transição de um lugar a outro, mas também de forma a forma, ou de estado a estado"44. A posição final de Leibniz seria, pois, a naturalista, que supõe uma passagem gradativa e contínua do animal para o homem - em outras palavras, o naturalismo seria o remédio contra o ocasionalismo.

As coisas não são, entretanto, tão simples. Como vimos acima, tanto na Teodiceia quanto na Monadologia, Leibniz hesita quando se trata de aplicar a noção de transcriação a mudanças qualitativas. Algumas vezes ele de fato supõe que, ao invés de transcriação, há, entre o homem e o animal, uma série densa de outros tipos de organismos desconhecidos por nós, organizados segundo um grau decrescente de racionalidade, de tal modo que a continuidade da mudança qualitativa seria preservada ${ }^{45}$. Em outras ocasiões, porém, ele afirma que "o mais estúpido dos homens [...] é incomparavelmente mais racional e ensinável do que o mais intelectual dos animais" ${ }^{36}$. Como vimos, a versão epistemológica da 
transformação de animais sensitivos em animais racionais nos dá alguma razão para privilegiar esses últimos textos ${ }^{47}$, que recorrem à transcriação para explicar a passagem do animal para o homem. Uma Alma só passaria, assim, à condição de Espírito quando, por uma operação particular de Deus, pudesse ter acesso a verdades necessárias e, através delas, refletisse sobre si mesma e se percebesse como um "eu". Mas, ao admitir a maior plausibilidade de um milagre contínuo, não se introduz uma restrição no caso do movimento local menos do que no caso da mudança de formas ou qualidades. Ou, em outras palavras, se os saltos quantitativos vão contra o Princípio de Continuidade, os saltos qualitativos também são incompatíveis com ele.

Para que isso fique mais claro, examinemos mais detidamente o significado da palavra "transcriação". É certo que o prefixo "trans”, que aparece no termo "transcriação", modificando assim a noção corrente de criação, não significa exatamente o mesmo tipo de mutação no intervalo de mais de trinta anos que separa o diálogo sobre o movimento e a Teodiceia. De fato, enquanto, na explicação do movimento corporal, a transcriação significava a destruição e a recriação dos corpos a cada momento do tempo em uma posição diferente, a transcriação da propriedade da racionalidade nos animais preserva esses últimos em sua substância: porque o acréscimo de perfeições essenciais só pode ser feito por milagre, e não por processos naturais, devemos concluir que a alma do

47 Jorgensen $(2013$, p. 90) prefere privilegiar os primeiros, propondo que a transcriação aplicada às almas não contraria o Princípio de Razão Suficiente porque se trataria aí de uma "continuous but non-natural transition from animal to human". 


\section{Dossiê Leibniz, Dissertatio - Volume Suplementar 03 U UFPel [2016]}

animal é modificada em sua essência, mas não destruída ${ }^{48}$ - o que parece mais próximo da ideia alquímica de transubstanciação do que da noção cristã de criação. Além disso, a transcriação envolvia, em 1676, uma ação repetida continuamente por Deus ao longo do movimento local dos corpos, ao passo que, em 1709, a transcriação da racionalidade nos animais parece ocorrer em um único momento de sua vida, o da concepção. Em ambos os casos, porém, o mesmo tipo de ação sobrenatural intervém, através de uma operação particular no movimento local da matéria, fazendo com que os elementos corporais envolvidos na mutação só possam ser entendidos como causas ocasionais da ação de Deus.

A diferença mais notável entre os fenômenos analisados em 1676 e em 1709 encontra-se na presença de um elemento teleológico presente na teoria da velhice e ausente na da juventude. Após formular, no $\int 82$ da Monadologia, a necessidade de os animais espermáticos sofrerem uma súbita "elevação" ao grau superior da racionalidade no momento da concepção, o $\ 83$ enuncia a principal diferença específica que é gerada por esse milagre: os Espíritos passam a ter consciência de que Deus é não apenas a causa eficiente de todas as coisas, mas também sua causa final, em direção à qual tudo se move e se transforma. As

48 Des Bosses critica inicialmente a tese da transcriação por ela envolver a destruição do animal e a criação de uma nova substância; Leibniz Ihe responde que a transcriação se limita a fazer surgir uma nova propriedade no animal, que continua a existir. Logo em seguida (carta de 30 de julho de 1709), tendo compreendido corretamente a tese leibniziana, objeta que ela implicaria a coexistência de duas enteléquias na mesma massa de matéria. Em 8 de setembro do mesmo ano, Leibniz explica que as perfeições acrescentadas miraculosamente por Deus às almas dos animais devem ser entendidas como "faculdades primitivas", isto é, independentes umas das outras. 
verdades necessárias conhecidas de forma inata pelos Espíritos tiveram, assim, um momento preciso de aparição, ainda que esse momento se situe, ao contrário do que sugeria Locke $^{49}$, fora do campo da experiência sensível, no instante preciso da formação do feto humano. São essas verdades necessárias que permitem que o Espírito se refira a si mesmo como um "eu" e que ele se dirija a Deus como o soberano Monarca da Cidade moral. O movimento final da Monadologia começa justamente nesse ponto, quando Leibniz passa a explicar como os homens entram em sociedade com Deus, e passam a ser habitantes de Sua cidade. A ruptura com os animais é dada precisamente por essa abertura escatológica ${ }^{50}$.

No artigo 87 da Teodiceia, pouco antes, portanto, do momento em que usará pela primeira vez o termo "transcriação" no livro, Leibniz nos conta a curiosa história de Hermolaüs Barbarus (1454-1495), um humanista italiano da Renascença que, atormentado por sua incompreensão do sentido do termo aristotélico "enteléquia", teria invocado o diabo com a intenção de que ele lhe explicasse o sentido desse conceito. A resposta que, dizem, obteve foi, segundo Leibniz, a seguinte: "Essa palavra, enteléquia, tira aparentemente sua origem da

\footnotetext{
49 À pergunta lockiana sobre "quando" o homem passa a fazer uso da razão seria assim respondida por Leibniz, anos mais tarde de ter escrito os Novos ensaios, por sua teoria da concepção e da formação dos fetos.

50 Uma série de teses teológicas relacionadas à salvação e à eucaristia - que, na discussão com De Volder, voltará a associar o problema da transformação à transcriação - pode ser usada para esclarecer a posição de Leibniz sobre a prioridade da causa final sobre a causa eficiente no que diz respeito à relação dos Espíritos com Deus. Dentre as teses católicas, a que afirma que Deus salva transformando e transforma salvando é uma das mais diretamente ligadas ao ponto em questão. Segundo essa tese, a salvação não nega a criação, mas acrescenta-lhe perfeições, direcionando-a a sua plenitude. É assim que o pão e o vinho são relacionados ao Cristo glorificado: a morte do Cristo é vivida pelos católicos como transformação, como irrupção do reino de Deus no mundo terreno.
} 


\section{Dossiê Leibniz, Dissertatio - Volume Suplementar 03 | UFPel [2016]}

palavra grega que significa perfeito", devendo, portanto, ser "exprimida em latim literalmente por perfectihabia, pois o ato é uma realização da potência". Leibniz termina essa história com uma observação irônica: Hermolaüs Barbarus "não tinha necessidade de consultar o diabo, como o fez, segundo se diz, para aprender apenas isso" 51 . Devemos constatar que a luz natural da razão não foi, porém, suficiente para que o próprio Leibniz eliminasse as ambiguidades que cercam sua própria abordagem da origem das formas.

Neste momento, Leibniz é exemplar de sua época: encontrando-se entre dois mundos, ele ilustra como poucos a ruptura radical entre homens e animais e, ao mesmo tempo, a nascente tendência para sua indiferenciação. Que a indecisão diante dessa fronteira indiscernível o faça relançar a "máquina antropológica”, para voltar à expressão de Agamben, talvez seja apenas mais um caso em que damos alguns passos para trás para melhor saltar. Aliás, é curioso como a metáfora expressa pelo filosofema "A natureza não dá saltos" convive, de forma aparentemente pacífica, nos escritos de Leibniz, com essa outra metáfora, a de que "recuamos para melhor saltar": ruptura e continuidade são, ambas, requisitos da antropologia racional. $\mathrm{O}$ momento de aquisição da perspectiva finalista é uma espécie de ponto cego que não pode ser representado para si mesmo, como o olho que vê todo o campo visual, com exceção de sua própria posição nele. A vertigem que nos leva, ainda hoje, a tentar definir a "abertura" que somos, e que talvez os animais também sejam - e que talvez

$51 \mathrm{GP} \mathrm{VI,} 150$. 
sejamos justamente pelo fato de sermos animais -, os abismos que tal tentativa abre sob nossos pés, na medida em que temos de afirmar, simultaneamente, a nossa identidade e a nossa diferença com relação aos demais animais, mostra que ainda não conseguimos saltar sobre tais abismos, mas que, ao contrário, o recuo e o salto nos levam de volta ao mesmo ponto em que Leibniz já se encontrava, no começo do século XVIII, ou seja, no começo de nós mesmos.

\section{REFERÊNCIAS BIBLIOGRÁFICAS}

AGAMBEN, Giorgio. O aberto. O homem e o animal. Rio de Janeiro: Civilização Brasileira, 2013.

FICHANT, M. “Leibniz e as máquinas da natureza”. In: revista Dois Pontos. Vol. 2, n. 1, 2005. . 'Postface: "Plus Ultra"”. In De l'Horizon de la Doctrine Humaine: Apokatástasis panton (La Restitution Universelle). Paris: J.Vrin, 1991.

KULSTAD, Mark. Leibniz on Apperception, Consciousness, and Reflection. München: Hamden; Wien: Philosophia, 1991.

LEIBNIZ, G. W. De l'Horizon de la Doctrine Humaine: Apokatástasis Panton (La Restitution Universelle). FICHANT, M. (ed. e trad.). Paris: J.Vrin, 1991. 
. Nowveaux essais sur l'entendement bumain. Paris:

Flammarion,1990.

. Opuscules et Fragments Inédits Extraits des Manuscrits de la

Bibliothèque Royale de Hanovre. COUTURAT, L. (ed.). Hildesheim; Zürich; New Yourk: Georg Olms Verlag, 1988.

. Die philosophischen Schriften. GERHARDT, C. I. (ed.). 7 Bände,

Berlin 1875-1890.

. Sämtliche Schriften und Briefe, herausgegeben von der Deutschen

Akademie der Wissenschaften. Darmstadt, 1923; Leipzig, 1938; Berlin, 1950 e cont.

MALEBRANCHE. Meditations chrétiennes et métaphysiques. Paris : J. Vrin, 1967.

MORGENSEN, L. "By Leaps and Bounds: Leibniz on Transcreation, Motion, and the Generation of Minds". In: The Leibniz Review, Vol. 23, 2013.

RASHED, M. "Natural philosophy". In: The Cambridge Companion to Arabic Philosophy. Cambridge: Cambridge University Press, 2005.

ROGER, J. “Lhistoire naturelle au XVIIle siècle: de l'échelle des êtres à lévolution”, 1990. In: $\quad$ http://www.persee.fr/web/revues/home/prescript/article/rhs_01514105_1991_num_44_3_4204 (consultado em 10/11/2014).

SMITH, J. E. H. Divine Machines. Leibniz and the Sciences of Life. Princeton: Princeton University Press, 2011. 